Лихачев С.А., Чернуха Т.Н., Рушкевич Ю.Н., Сидорович Э.К., Ажыкулова К.С., Линник О.В., Дымковская М.Н.

Республиканский научно-практический центр неврологии и нейрохирургии, Минск, Беларусь

Likhachev S., Charnukha T., Rushkevich Yu., Sidarovich E., Azhykulova K., Linnik O., Dymkovskaya M. Republican Research and Clinical Center of Neurology and Neurosurgery, Minsk, Belarus

Редкая форма наследственной нейродегенерации, ассоциированная с геном мембранного белка митохондрий с накоплением железа в мозге

\author{
A Rare Form of Hereditary Neurodegeneration Associated \\ with the Mitochondrial Membrane Protein Gene \\ with the Accumulation of Iron in the Brain
}

Резюме

В статье приведено описание собственного клинического наблюдения генетически подтвержденного диагноза, известного в зарубежной литературе как Mitochondrial membrane Protein-Associated Neurodegeneration (MPAN), относящегося к группе нейродегенеративных заболеваний с накоплением железа в головном мозге (ННЖМ). ННЖМ - клинически и генетически гетерогенная группа наследственных прогрессирующих болезней центральной нервной системы с выраженным накоплением железа в базальных ганглиях, проявляющимся прогрессирующим многосимптомным поражением центральной нервной системы с типичной MPТ-картиной. Характерно начало в детском возрасте, первыми симптомами заболевания являются дизартрия и нарушения походки, позже появляются пирамидные и экстрапирамидные симптомы, нарушения психики. ННЖМ, тип 4, - ННЖМ-4 - составляет 6-10\% из всех ННЖМ, на сегодняшний день описано не более 80 случаев генетически доказанной мутации в гене C19orf12.

Ключевые слова: нейродегенерация с накоплением железа в головном мозге, тип 4, экстрапирамидные симптомы, дистония, психические нарушения, молекулярно-генетическая диагностика, ботулинический токсин типа А, симптоматическая терапия.

Abstract

The article describes our own clinical observation of a genetically confirmed diagnosis known in the foreign literature as Mitochondrial membrane Protein-Associated Neurodegeneration (MPAN), which belongs to the group of neurodegenerative diseases with iron accumulation in the brain (NBIA). NBIA is a clinically and genetically heterogeneous group of hereditary progressive diseases of the central nervous system with a pronounced accumulation of iron in the basal ganglia, manifested by a progressive multisymptomatic lesion of the central nervous system with a typical MRI picture. The onset is characteristic in childhood, the first symptoms of the disease are dysarthria and gait 
disturbances, later pyramidal and extrapyramidal symptoms, mental disorders appear. MPAN, type 4 makes up $6-10 \%$ of all NBIA; to date, no more than 80 cases of genetically proven mutation in the C19orf12 gene have been described.

Keywords: neurodegeneration with iron accumulation in the brain, type 4, extrapyramidal symptoms, dystonia, mental disorders, molecular genetic diagnostics, botulinum toxin type A, symptomatic therapy.

\section{- ВВЕДЕНИЕ}

Нейродегенерация с накоплением железа в мозге (ННЖМ), известная больше под названием Neurodegeneration with brain iron accumulation (NBIA), представляет собой клинически и генетически гетерогенную группу наследственных прогрессирующих болезней центральной нервной системы, для которых характерно накопление железа в базальных ганглиях, связанного с нарушением обмена металлов [1]. До 2001 г. была известна единственная форма ННЖМ - это ННЖМ-1, или болезнь Галлевордена - Шпатца. В 1922 г. два ученых из Германии, Юлиус Галлеворден и Гуго Шпатц, занялись изучением следующего клинического случая: в семье из 12 человек у 5 сестер наблюдались прогрессирующая деменция и дизартрия. Данные аутопсии показали, что в многочисленных областях головного мозга ткани были окрашены в коричневый цвет. В частности, интерес представляла окраска в области черной субстанции и базальных ядер. Описанное заболевание получило название болезнь Галлевордена - Шпатца, которое использовалось вплоть до недавнего времени, пока не была установлена роль исследователей в проведении экспериментов над заключенными в нацистской Германии, после чего эпоним сменили на нейродегенерацию с отложением железа в головном мозге (Neurodegeneration with brain iron accumulation, NBIA) [2].

В начале XXI в. (в 2001 г.) была выявлена связь между ННЖМ-1 и геном PANK2, который кодирует пантотенаткиназу-2 и участвует в регуляции биосинтеза коэнзима А, описано более 130 мутаций гена во всех 7 экзонах. До сегодняшнего времени ННЖМ-1 является самой распространенной формой (35-50\%) из всех ННЖМ, наследуется по аутосомнорецессивноному типу наследования. Начало болезни - на 1-2-м десятилетиях, чаще в 5-7 лет. В большинстве случаев в ее клинической картине преобладают экстрапирамидные симптомы (дистония, которая может быть и ДОФА-зависимая), пирамидный синдром, дизартрия, когнитивные расстройства, деменция, атрофия зрительных нервов, пигментные дегенерации сетчатки.

В течение последующих лет были открыты и другие мутации и фенотипы нейродегенерации: в 2006 г. была обнаружена ННЖМ2 с аутосомно-рецессивным типом наследования. ННЖМ-2 связана с мутацией гена PLA2G6, кодирующего фосфолипазу A2, приводящей к возникновению PLA2G6-ассоциированной нейродегенерации (PLAN). Для ННЖМ-2 характерно раннее начало, прогрессирующие атаксии и спастичность, выраженная аксиальная гипотония, утрата психомоторных навыков, атрофия зрительных нервов с потерей зрения, пациенты умирают до 10 лет. 
ННЖМ-3 мутация в гене FTL имеет аутосомно-доминантный тип наследования с Х-сцепленным доминантным наследованием. ННЖМ-3 проявляется в детском и подростковом возрасте двигательными расстройствами, трудностями в артикуляции речи, а также когнитивными и психическими расстройствами [3].

В 2011 г. ген C19orf12 (НHЖМ-4) был идентифицирован как ответственный за нейродегенерацию, ассоциированную с белками митохондриальной мембраны (MPAN). Описана сравнительно недавно - в 2011 г. Hartig M., luso A., Haack T. [1].

Недавно в спектр NBIA включили еще одно заболевание: бета-пропеллерный белок-ассоциированную нейродегенерацию (BPAN) - НHЖМ5, с аутосомно-доминантным типом наследования с Х-сцепленным доминантным наследованием. Клинически проявляется эпилепсией с дебютом в раннем детском возрасте, умственной отсталостью со стереотипиями, двигательными нарушениями, которые в детском возрасте проходят под маской детского церебрального паралича, а с подросткового периода усиливаются проявлениями паркинсонизма, развиваются осложнения в виде торсионной дистонии.

На сегодняшний день известно более 9 типов ННЖМ, отличающихся между собой мутациями в различных генах. Диагноз подтверждается исключительно молекулярно-генетическим анализом. Большинство ННЖМ начинаются в детском возрасте, имеют схожую клиническую картину в виде прогрессирующего многосимптомного поражения центральной нервной системы, легко визуализируются при МРТ-, КТ-исследовании [3].

\section{- ОПИСАНИЕ СОБСТВЕННОГО КЛИНИЧЕСКОГО НАБЛЮДЕНИЯ}

Пациентка С., 19 лет, не работает, является инвалидом II группы, поступила в неврологическое отделение РНПЦ неврологии и нейрохирургии с жалобами на нарушение ходьбы, насильственный поворот головы вправо, периодические боли в шее, дрожание рук. Со слов родителей изменилось поведение, стала более беспокойна, мнительна, периоды благодушного настроения сменяются приступами гнева, ухудшилась память, речь стала более растянута.

Со слов матери, болеет с 10-летнего возраста, когда появилось подворачивание левой стопы при ходьбе. Через год после дебюта заболевания ребенок начал ходить на носках, симптоматика со временем прогрессировала, отмечено нарушение ритма речи, поведенческие нарушения (эйфория), в возрасте 13-14 лет появился насильственный поворот головы. В течение последнего года симптомы постепенно нарастали, стала хуже передвигаться, со слов родителей стала более упряма, многократно повторяет одинаковые вопросы, бывают периоды агрессии.

Анамнез жизни: ребенок от первых родов, роды в срок, масса 2870 г, Апгар - 8/9. Со слов матери раннее моторное и речевое развитие без особенностей.

Из семейного анамнеза: оба родителя здоровы, имеет здорового младшего брата. Длительное время лечилась в медицинских учреждениях с различными диагнозами: детский церебральный паралич, последствия нейроинфекции, пантотенаткиназная нейродегенерация. 
В 2014 г. на МРТ головного мозга отмечалось выраженное снижение сигнала от бледного шара и черной субстанции во всех последовательностях. При проведении диффузионно-взвешенной томографии в этих зонах определяется неоднородность магнитного поля (за счет отложения железа). Заключение: МР-картина в пользу нейродегенеративного заболевания.

При объективном осмотре: низкий рост - 152 см, вес 45 кг, АД 110/70 мм рт. ст., пульс 86 уд. в мин., температура тела $36,0^{\circ} \mathrm{C}$.

В неврологическом статусе: в сознании, ориентирована в полном объеме, снижена память на текущие события, снижена концентрация внимания, критика к своему состоянию. Эйфорична, добродушна, обстоятельна, многократно повторяет одни и те же вопросы, общительна, охотно вступает в контакт. При несогласии с ее просьбами может быть агрессивна, кричит, размахивает руками. Зрачки равновеликие. Черепные нервы: движения глаз в полном объеме, спонтанного нистагм нет. Легкая асимметрия носогубных складок. Язык по средней линии. Легкая дизартрия, речь растянута. Глоточный рефлекс вызывается. Тонус в конечностях изменен: в верхних конечностях повышен по экстрапирамидному типу, в нижних конечностей повышен по центральному типу. Сила в конечностях 5 баллов, верхняя и нижняя пробы Барре отрицательные. Глубокие рефлексы на руках оживлены, зоны расширены, на руках слева выше, на ногах равновеликие. Симптом Якобсона - Ласка, верхний симптом Россолимо с обеих верхних конечностей - положительны. С нижних конечностей патологические симптомы: Бабинского, Россолимо с обеих сторон. В позе Ромберга устойчива. При ходьбе отмечается динамическая эквиноварусная установка стоп, больше слева, затрудняющая передвижение. Пальценосовую пробу справа выполняет удовлетворительно, слева - с легкой интенцией, пяточно-коленную - не может выполнить вследствие тонических нарушений. Убедительных расстройств чувствительности не выявлено. Менингеальных знаков, симптомов натяжения нет. Ограничен объем пассивных движений тазобедренных суставов (сгибание при выпрямленной в коленном суставе ноге до 30-40 градусов, ограничены внутренняя и наружная ротация бедра); ограничено разгибание в голеностопных суставах (в большей степени слева) с эквиноварусной установкой стоп. Правосторонний тортиколлис, тоникоклонический вариант. Постурально-кинетический тремор верхних конечностей. Дистоническая установка правой руки со сгибанием в локтевом суставе. Напряжение и гипертрофия грудино-ключичнососцевидных мышц (более выраженная слева), трапециевидной мышцы справа. Эквиноварусная установка стоп, больше слева, пациентки С. представлена на рис. 1.

Психолог: жалобы самостоятельно не формулирует. Контакту доступна, ориентирована в полном объеме, эмоциональный фон - благодушна, несколько эйфорична, критика к своему состоянию снижена. Когнитивный статус: умеренное снижение по смешанному типу. Акалькулия, оптико-пространственная агнозия. Речь дизартрична. MMSE 22 балла, FАВ - 12. Тест рисования часов - 2 балла.

Психиатр: F07.8 - Органическое расстройство личности и поведения с выраженным когнитивных снижением. 


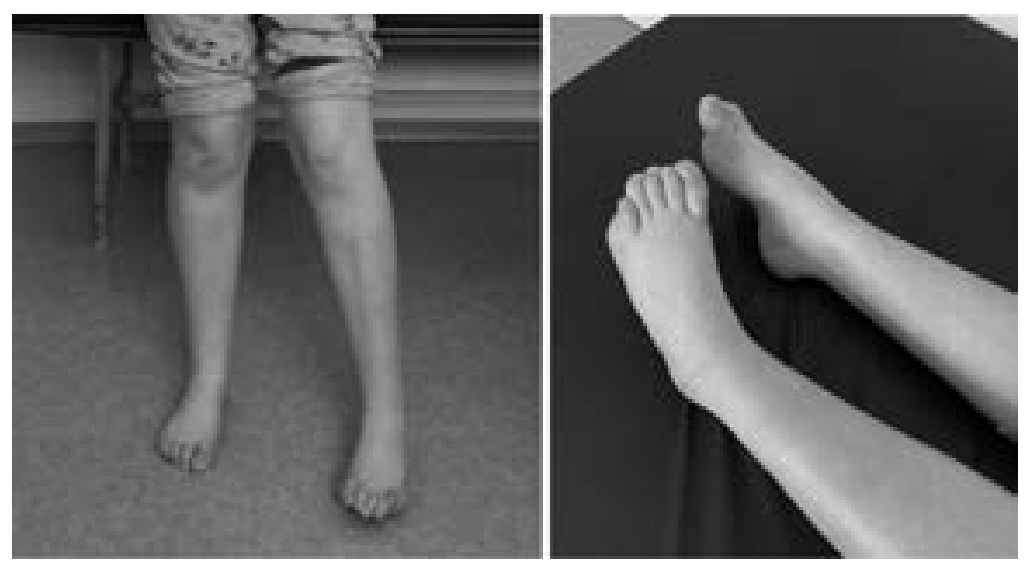

Рис. 1. Фотография ног пациентки: наблюдается эквиноварусная установка стоп

Fig. 1. In this picture we can see the talipes equinovarus

МРТ головного мозга: отмечается выраженное снижение сигнала от бледного шара и черной субстанции во всех последовательностях. При проведении диффузно-взвешенной томографии в данных зонах определяется неоднородность магнитного поля (за счет отложения железа). Заключение: МР-картина в пользу нейродегенеративного заболевания.

На рис. 2 представлен скан МРТ головного мозга в Т2-режиме, стрелкой обозначено накопление железа в области бледного шара.

ЭМНГ: признаки аксональной полинейропатии.

Офтальмолог: Visus OD/OS = 0,2/0,2; не корригируется. Рефрактометрия: OD sph. -0,25 cyl. -0,5 ax 23: OS sph. +0,0 cyl. -0,5 ax 4. Установлено нарушение цветоощущения по таблице Рабкина: III - 6, IV - 9, V - нет,

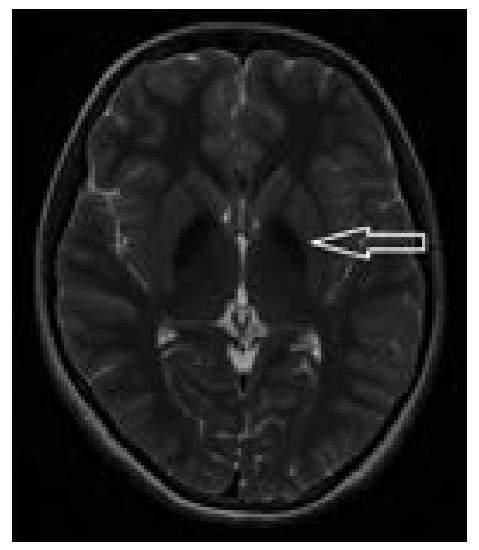

Рис. 2. МРТ-картина головного мозга в Т2-режиме

Fig. 2. MRI of the brain in T2-weighted 
$\mathrm{VI}$ - нет, VII - 6, VIII - 9, IX - 10, X - 03, XI - треугольник, XII - 12, XIII - нет, XIV - 19, XV - треугольник, 1, квадрат, XVI - нет, XVII - 10, XVIII - 8, XIX - 15, XX - нет, XXI - 9, XXII - нет, приобретенные: OD: XXIII - 13, XXIV - 16, XXV - нет, OS: XXIII - 16, XXIV - 15, XXV - нет. Передний отрезок: OU спокойны, среды прозрачны. Глазное дно: ОU - ДЗН бледноваты, бледно-серые височные половины, контуры четкие. Ход и калибр сосудов не изменен. A:B=2:3. Макула без патологии. Видимая периферия глазного дна без особенностей. Заключение: частичная атрофия обоих зрительных нервов. Дейтеранопия.

ИФА на сифилис - отрицательный.

Анализ крови на ВИЧ - отрицательный.

Анализ крови на медь, церрулоплазмин в пределах нормальных значений.

Общий и биохимический анализы крови, ЭКГ, общий анализ мочи в пределах нормальных значений.

Выполнен генетический анализ крови в институте молекулярной генетики Российской академии наук (Москва) методом прямого автоматического секвенирования экзома. Выявлена гомозиготная мутация в 3-м экзоне гена C19orf12 (chr19:30193864del11, rs515726204), приводящая к сдвигу рамки считывания, начиная с компаунд-гетерозиготной формы вместе с другими мутациями у пациентов с нейродегенерацией с накоплением железа в мозге, тип 4.

На основании клинического осмотра, данных дополнительных методов исследования, результатов генетического анализа был выставлен диагноз: наследственное нейродегенеративное заболевание с накоплением железа в подкорковых ядрах, ассоциированное с белками митохондриальной мембраны (MPAN) с генерализованной дистонией (в виде легкого правостороннего тортиколлиса, выраженной эквиноварусной установки стоп), умеренным постурально-кинетическим тремором верхних конечностей, двусторонней пирамидной недостаточностью, частичной нисходящей атрофией зрительных нервов ОU, умеренно выраженными когнитивными нарушениями. F07.8.

Для коррекции симптомов заболевания у пациентки за годы лечения использовались различные группы препаратов, при появлении эквиноварусной установки стоп положительный эффект наблюдался на фоне приема баклофена, 2 года назад выполнено введение препарата ботулинического токсина типа А в мышцы шеи, с нормотимичекой целью пациентке подобрана доза карбамазепина по схеме: 100 мг утром и в обед, 200 мг вечером.

Ввиду тяжелого нарушения походки из-за выраженной эквиноварусной установки стоп, больше слева, которое было одним из основных инвалидизирующих причин для лечения, проведена ботулинотерапия - ботулиническим токсином типа А.

Под ультразвуковой навигацией введено 800 ЕД препарата ботулинического токсина типа А (диспорт) в мышцы левой голени: $\mathrm{mm}$. gastrocnemius, soleus, tibialis posterior. Побочных эффектов, осложнений не отмечено. Увеличился объем разгибания в левом голеностопном суставе, менее выражена эквиноварусная установка левой стопы при ходьбе, увеличилась скорость ходьбы. 


\section{- ОБСУЖДЕНИЕ}

Приведен клинический случай нейродегенеративного заболевания с накоплением железа, связанного с геном C19orf12. Ген C19orf12 принадлежит к генам open reading frame (открытая рамка считывания), к которым относится около 1250 генов генома человека. Белок C19orf12 локализован в митохондриальной мембране клеток головного мозга, крови, адипоцитов; предполагается его влияние на обмен жирных кислот и аминокислот (валин, лейцин, изолейцин). У пациентов-носителей гена белок C19orf12 отсутствует [3]. В мышечном биоптате пациентов при электронной микроскопии находят тонкие признаки патологии митохондрий. Среди зарегистрированных мутаций C19orf12 мутация Gly69ArgfsX10 распространена у людей польской национальности и выявляется в большинстве семей восточноевропейского происхождения. У большинства пациентов с данной мутацией гена были также дегенерация сетчатки и атрофия зрительного нерва разной степени, ни у кого не приведшая к слепоте [4].

Возраст начала ННЖМ-4 - от 5 до 20 лет. Как правило, первыми симптомами заболевания являются дизартрия и нарушения походки, позже появляются пирамидные симптомы (спастика, симптом Бабинского), экстрапирамидные нарушения (дистония, хорея, паркинсонизм). Характерным симптомом являются нарушения психики: импульсивное или компульсивное поведение, эмоциональная лабильность, депрессии, психозы, позже присоединяется снижение когнитивных функций. На ЭНМГ наблюдается картина аксональной полинейропатии. Офтальмологи также могут диагностировать атрофию зрительного нерва у пациентов с ННЖМ-4. Дополнительно могут быть жалобы на потерю веса, дисфункцию кишечника и мочевого пузыря.

Заподозрить диагноз помогают характерные изменения на МРТснимках. Наблюдаются поражение бледного шара и черной субстанции снижение интенсивности Т2-сигнала, но повышенная интенсивность сигнала с переднемедиальной части бледного шара, окончательный диагноз устанавливается на основании генетического исследования $[4,5]$.

Особенностями клинической картины ННЖМ-4 по сравнению с «классической» ННЖМ-1 являются: более медленное течение, менее выраженные нарушения интеллекта и психики, а также преобладание пирамидных симптомов над экстрапирамидными. Характерной чертой является аксональная полинейропатия при ЭНМГ. Для МРТ-картины всех форм ННЖМ характерно поражение бледного шара и черной субстанции, а именно снижение интенсивности Т2-сигнала [2, 6]. Для ННЖМ-1 типична повышенная интенсивность сигнала с переднемедиальной части бледного шара, характерен симптом «глаз тигра» [8].

Нетипичность «глаз тигра» для ННЖМ-4 - очень важный дифференциально-диагностический признак ННЖМ на долабораторном этапе. МРТ головного мозга - основной и высокоинформативный инструментальный метод диагностики, но характерные изменения появляются не до клинических симптомов (как при ряде наследственных болезней) и даже не одновременно с ними, а спустя время, нередко годы, причем в динамике не нарастают [7].

ННЖМ-4 нужно дифференцировать с ювенильным паркинсонизмом, который имеет схожую клиническую картину и ранний дебют 
заболевания. Типичный возраст начала - около 20 лет. Клиника проявляется скованностью движений, тремором в руках, изменением походки, достаточно часто встречается дистонический гиперкинез. Синдром паркинсонизма часто сочетается с дистонией (писчий спазм, кривошея, ларингеальная дистония, дистония конечностей), наблюдаются пирамидные симптомы [9].

Отличается ювенильный паркинсонизм от ННЖМ-4 тем, что имеется наличие флуктуации выраженности симптомов паркинсонизма и дистонии на протяжении дня, при этом наилучшее состояние отмечается утром или после сна, а к вечеру тяжесть клинических проявлений возрастает, тогда как при ННЖМ-4 клиника в течение дня не меняется. Особое значение при дифференциальной диагностике имеет и то, что при ювенильном паркинсонизме отмечается выраженный положительный эффект от препаратов леводопы в минимальной дозе, тогда как при ННЖМ-4 леводопа не оказывает существенного эффекта. Самым высокоточным методом диагностики в пользу того или иного заболевания служит молекулярно-генетический анализ. Патологический ген аутосомно-рецессивного ювенильного паркинсонизма картирован на длинном плече 6-й хромосомы в фокусе 6q25.2-q27 [10].

Следующая болезнь, которую нужно дифференцировать с ННЖМ, ДОФА-зависимая форма дистонии, которая имеет схожую клиническую картину в дебюте заболевания. ДОФА-зависимая дистония является аутосомно-доминантным заболеванием, связанна с геном дофаминового обмена - циклогидрогеназой-1, гена, получившего название GCH 1, который был картирован на хромосоме 14q22.1. При наличии мутаций в гене GCH1 наблюдается нарушение функции данного фермента, что приводит к нарушению синтеза дофамина в нейронах черной субстанции. При назначении препаратов леводопы синтез дофамина восстанавливается, и у пациентов наблюдается значительный положительный эффект. Данное заболевание может проявляться стертыми клиническими вариантами, таким как фенотип атетоидного церебрального паралича, фокальной дистонии конечности, непостоянной эквиноварусной позы стоп (главным образом при ходьбе) либо изолированным статокинетическим тремором рук [11]. Диагностическим отличием ДОФА-зависимой дистонии от ННЖМ является высокая чувствительность к препаратам леводопы даже в минимальных дозах. Сравнительно недавно появились публикации о выявлении аутосомно-рецессивных форм ДОФА-зависимых форм дистонии, при которых выявлены повреждения других генов, также связанных с нарушением обмена дофамина в головном мозге. Окончательным методом для подтверждения того или иного заболевания является генетическое тестирование для выявления мутаций в различных генах [12].

Известна также другая форма торсионной дистонии - ДОФА-независимая, которую также нужно дифференцировать с ННЖМ-4. Генерализованная дистония связанна с мутацией в гене DYT1, дебют заболевания также проявляется в детском и подростковом возрасте. Клинически наблюдается фокальная и генерализованная дистония, нечувствительность к препаратам леводопы, в редких случаях может наблюдаться постуральный тремор рук, заикание вследствие дистонии оральной мускулатуры. Кроме генетических отличий этого заболевания от ННЖМ-4, 
отмечается, что при ДОФА-независимой дистонии не выявляются структурные изменения при нейровизуализации [13].

ННЖМ-4 нужно дифференцировать с гепатолентикулярной дегенерацией (ГЛД), другое название - болезнь Вильсона - Коновалова, которая также наследуется по аутосомно-рецессивному типу и проявляется в молодом возрасте. За развитие заболевания ответственен ATP7В-ген, локус 13q14. Органами-мишенями при ГЛД в первую очередь являются печень и головной мозг. В основе патогенеза ГЛД лежит генетически обусловленное нарушение метаболизма меди, ведущее к избыточному накоплению ее в органах-мишенях и вызывающее эндогенную интоксикацию медью $[14,15]$.

Клиника ГЛД характеризуется большим полиморфизмом неврологических и соматических проявлений. Поражение печени избытком «свободной» меди проявляется циррозом печени. Поражение мозга приводит к развитию тяжелой неврологической симптоматики: дрожанию конечностей и всего туловища, повышению мышечного тонуса, иногда сопровождающемуся болезненными спазмами, нарушением речи, глотания, снижению интеллекта. Для подтверждения диагноза в пользу болезни Вильсона - Коновалова требуется исследование крови на медь и церрулоплазмин, также исследование мочи на медь. Дополнительным инструментальным методом исследования при ГЛД является УЗИ печени, при котором наблюдается развитие «вильсоновского гепатита» (гепатоза) с последующим переходом в атрофический нодулярный цирроз печени.

МРТ головного мозга показывает картину атрофии больших полушарий, мозжечка, подкорковых структур с соответствующим расширением субарахноидальных пространств и желудочковой системы, а также очаги усиления сигнала в Т2-режиме в области лентикулярных ядер и таламуса. Важным диагностическим критерием является отложение меди в роговице (по краю радужной оболочки), что обусловливает формирование кольца Кайзера - Флейшера - буро-зеленоватого пигмента. Также идентификация гена ГЛД методом прямой и косвенной ДНК-диагностики. Важно помнить об этом потенциально курабельном заболевании. Так, своевременное назначение препаратов D-пеницилламина (купренила) приостанавливает прогрессирование заболевания и вызывает постепенный регресс симптомов [12].

\section{ЗАКЛЮЧЕНИЕ}

В статье приведено описание собственного клинического наблюдения генетически подтвержденного диагноза, известного в зарубежной литературе как Mitochondrial membrane Protein-Associated Neurodegeneration (MPAN), относящегося к группе нейродегенеративных заболеваний с накоплением железа в головном мозге. ННЖМ-4 является редко встречаемой патологией в клинической практике, которая недостаточно изучена и описана в русскоязычной литературе. В статье рассмотрена типичная клиническая картина, обсужден дифференциальный диагноз, окончательный диагноз устанавливается по данным МРТ и анализа крови на генетику. Лечение заболевания симптоматическое, ведение пациентов с ННЖМ должно быть совместно с психиатром, офтальмологом, логопедом, травматологом-ортопедом. К сожалению, 
заболевание имеет неуклонно прогрессирующее течение, большинство пациентов утрачивают способность самостоятельно передвигаться на 3-м десятилетии. Рекомендовано назначение центральных миорелаксантов (баклофен), нормомиметиков и противосудорожных средств (карбамазепин, вальпроевая кислота и др.), антидепрессантов, витаминов группы В. Для коррекции дистонии и локального гипертонуса эффективно применение локальных инъекций ботулинического токсина типа A.

Вклад авторов: С.А. Лихачев - разработка дизайна исследования; Т.Н. Чернуха, Ю.Н. Рушкевич, Э.К. Сидорович, О.В. Линник, М.Н. Дымковская - получение данных для анализа, анализ полученных данных; Т.Н. Чернуха, Ю.Н. Рушкевич, К.С. Ажыкулова - написание текста рукописи; Т.Н. Чернуха, Ю.Н. Рушкевич, К.С. Ажыкулова - обзор публикаций по теме статьи; С.А. Лихачев, Т.Н. Чернуха, Ю.Н. Рушкевич, Э.К. Сидорович, Линник О.В. - редактирование.

Authors' contribution: S. Likhachev - research design development; T. Charnukha, Y. Rushkevich, E. Sidorovich, O. Linnik, M. Dymkovskaya obtaining data for analysis, analyzing the data obtained; T. Charnukha, Y. Rushkevich, K. Azhykulova - writing the text of the manuscript; T. Charnukha, Y. Rushkevich, K. Azhykulova - a review of publications on the topic of the article; S. Likhachev, T. Charnukha, Y. Rushkevich, E. Sidorovich, O. Linnik - editing.

Конфликт интересов. Авторы заявляют об отсутствии конфликта интересов.

Conflict of interest. The authors declare no conflict of interest.

\section{- ЛИТЕPATYPA/REFERENCES}

Hartig M., luso A., Haack T. et al. (2011) Absence of an Orphan Mitochondrial protein, C19orf12, causes a distinct clinical subtype of neurodegeneration with brain iron accumulation. Amer J Hum Genet, vol. 89, pp. 543-550.

2. Meyer A. et al. (1958) The Hallervorden-Spatz syndrome. In: Greenfield J.G. (ed.): Neuropathology. London: Edward Arnold Ltd. pp. 525.

3. Zakharova E.Yu., Rudenskaya G. (2014) A new form of hereditary neurodegeneration with iron accumulation in the brain: clinical and molecular genetic characteristics. Journal. neurology and psychiatry them. Korsakov, no 1, pp. 4-12. (In Russian)

Hayflick S.J., Kurian M.A., Penelope H. (2018) Neurodegeneration with brain iron accumulation. doi: 10.1016/B978-0-444-63233-3.00019-1.

5. Gore E., Appleby B.S., Cohen M.L. et al. (2016) Clinical and imaging characteristics of late onset mitochondrial membrane protein-associated neurodegeneration (MPAN). pp. 476-483. doi: 10.1080/13554794.2016.1247458

6. Gregory A., Lotia M., Jeong S.Y. et al. (2019) Autosomal dominant mitochondrial membrane protein-associated neurodegeneration (MPAN). Genomic Med. vol. 7 no 7 , pp. e00736. doi: 10.1002/mgg3.736.

Hogarth P., Gregory A., Kruer M. et al. (2013) New NBIA subtype: genetic, clinical, pathologic, and radiographic features of MPAN. Neurology, vol. 80, pp. $268-275$. Guillerman R.P. (2000) The eye-of-the-tiger sign Radiology. doi: 10.1148/radiology, no. 9, .217.3.ro0dc31895.

. Jones A.C., Yamamura Y., Almasy L. et al. (1998) Autosomal recessive juvenile parkinsonism maps to 6q25.2-q27 in four ethnic groups: detailed genetic mapping of the linked region. doi: 10.1086/301937.

10. Maiti P., Manna J., Dunbar G.L. (2017) Current understanding of the molecular mechanisms in Parkinson's disease: Targets for potential treatments. Trans/ Neurodegener. doi: $10.1186 /$ s40035-017-0099-z

Charnukha T. (2009) Polymorphism of clinical manifestations of dopa-dependent forms of muscular dystonia. Neurology and neurosurgery in Belarus, no 4, pp. 49-53.

Stock V., Ivanova-Smolenskaya I., Levin O. (2002) Extrapyramidal Disorders. Diagnostic and Treatment Guide, pp 608-620

13. Lee W.W., Jeon B., Kim R. (2018) Expanding the Spectrum of Dopa-Responsive Dystonia (DRD) and Proposal for New Definition: DRD, DRD-plus, and DRD Look-alike. J Korean Med Sci. 2018. doi: 10.3346/jkms.2018.33.e184

14. Kathawala M, Hirschfield GM. (2017) Insights into the management of Wilson's disease. Therap Adv Gastroenterol., vol. 10, no 11, pp. 889-905. doi: 10.1177/1756283X17731520

15. Chen C., Shen B., Xiao J.J., Wu R., Duff Canning S.J., Wang X.P. (2015) Currently Clinical Views on Genetics of Wilson's Disease. Chin Med. J., vol. 128, no 13, pp. 1826-1830. doi:10.4103/0366-6999.159361 